\title{
The Effects of Ownership Structure on Time Spend by Physicians with Patients
}

\begin{abstract}
Serdar Aydin ${ }^{1 *}$
${ }^{1}$ University of South Carolina, USA

*Corresponding Author: serdaraydin7777@gmail.com

Citation: Aydin, S. (2020). The Effects of Ownership Structure on Time Spend by Physicians with Patients. European Journal of Environment and Public Health, 4(1), em0037. https://doi.org/10.29333/ejeph/6292

\section{ARTICLE INFO}

Received: 2 Nov. 2019

Revised: 5 Nov. 2019

Accepted: 11 Nov. 2019

ABSTRACT

As the U.S. seeks to increase the quality of health care, both the quality and quantity of time physicians spend with patients will continue to be an important factor as in the last decades. In today's healthcare environment, time is more valuable than before and the payment system, like fee-for service, encourages physicians to care for more patients but spend less time with them. Inherently, time spent with the physician is an important indicator for patients to see the total care. Based on this assumption, patient satisfaction cannot be fulfilled without a sufficient amount of time spent with the physician during the examination. If the physicians do not spend enough time with patients, they cannot understand the patients' problems and history of illness. How can we achieve better outcome for patients if we do not understand their problems and concerns? At the same time, we know that involving patients in the decision-making process is important to get better results. Overall, the amount of time spent with patients indeed is an important indicator of good quality of health services and must be continuously monitored by health administrators to improve effectiveness and increase health care quality.
\end{abstract}

Keywords: time spend with patient, time factors, ownership, quality of healthcare

\section{INTRODUCTION}

To be effective as medical care providers, physicians must use their time effectively with the development of medical science. The profession of physicians has become more complex over the years requiring collaboration and coordination of various service providers. If physicians do not spend enough time with patients, it will be difficult to understand the patients' problems and possible causing of health condition. In medical care practice, involving patients in the decision making process is important to get better results. The time a physician spends with a patient is important because it has significant impact on patient satisfaction (Dugdale, Epstein, \& Pantilat, 1999; Ha \& Longnecker, 2010; Lin et al., 2001; Tongue, Epps, \& Forese, 2005). Patient satisfaction is also positively changed when they have opportunity to be involved in the decision-making process and feel informed (Kaplan, Greenfield, Gandek, Rogers, \& Ware, 1996; Kaplan, Greenfield, \& Ware Jr, 1989; Laine et al., 1996). Involvement depends on how much time a physician spends with a patient. Optimum visit length is achieved when physician strike balance of quality and quantity. Overall, the amount of time spent with patients is an important indicator of quality of health services.
While physicians are trying to be more efficient, time management is an important indicator for better efficiency. Therefore, effectively time spent has to be managed in every department giving care services. For instance, the ultimate goal of the emergency department director, or anyone on the staff of the emergency department for that matter, is supposed to attain maximum efficient as well as effective. There have been some factors reduce doctors' efficiency such as paperwork, rework, and duplicate work or inappropriate work, $31 \%$ of the average healthcare worker's time was wasted through those factors which reduces amount of time they can spend with patient (Hollingsworth, Chisholm, Giles, Cordell, \& Nelson, 1998). Generally, administrative forces and economic concerns have impacted on physicians' time with patients. The incentives are implemented to care for the greatest number of patients and reduce the overall use of resources. Because of the limited working hours in a day, physicians reduce the time spent with each patient during an appointment (Dugdale et al., 1999).

Due to the payment system and Physicians' politic powers, the healthcare is functioned like a monopoly and oligopoly market controlled by mainly physicians. Physicians time value has never picked up like today what it is as well the power of this occupation. One study concluded that almost fifty percent of American physicians have a decline in the time they spent 
with patients between 1992 and 1995. This decline in the time physicians spent with patients has been growing day after day (Rhodes, McFarland, Finch, \& Johnson, 2001). For this reason, time spent by physicians during patient visits and the factors affecting it have been studied at the past, and would be continue to be studies in the future.

As the U.S. seeks to increase the quality of health care, both the quality and quantity of time physicians spend with patients will continue to be an important factor as in the last decades. In today's healthcare environment, time is more valuable than before and the payment system, like fee-for service, encourages physicians to care for more patients but spend less time with them. Roter suggests that because technology and methodology have evolved, observing doctor-patient relationships is not as complicated as it was previously, and many studies have therefore been done regarding this relationship (Roter, Hall, \& Katz, 1988). Although the Roter study is an old study, it is still relevant and suggests that studying doctor-patient relationships is important.

Hollingsworth et al. indicate "the goals of health care managers, policy makers, and workers include improving efficiency and productivity, reducing waste, redistributing resources, and decreasing costs. Achieving these goals depends in part on understanding the type of tasks health care workers perform and the amount of time they spend accomplishing them" (Hollingsworth et al., 1998).

There are a number of studies that have examined how and where physicians spend their time. McDonald and Dzwonczyk analyzed time and event data and found that only $17 \%$ of physicians' time was spent in direct contact with patients (McDonald \& Dzwonczyk, 1988). Another study reported that physicians spent approximately $38 \%$ of their time charting, $5 \%$ consulting, 55\% with patients (Mamlin \& Baker, 1973). One study concluded that the lack of time during the office visit was the reason for physicians not to focus on preventive services (Yarnall, Pollak, Østbye, Krause, \& Michener, 2003). Preventive care visits gave physicians more time to talk about cholesterol, exercise, and blood pressure than chronic care visits (Pollak et al., 2008). Physicians who spent more time with patient also made more statements about health education and prevention. In general, these studies imply that increasing the time physician spend with patients will lead to better health outcome (Anderson, Camacho, \& Balkrishnan, 2007; Dugdale et al., 1999; Lin et al., 2001). However, there is no gold standard on how much time physicians spend with a patient. The amount of time physicians spends with patients on the average vary widely across different countries. For instance, in the United States and Sweden, visit lengths are usually in between 10 to 20 minutes, whereas in Great Britain it is in between 5 to 8 minutes (Andersson \& Mattsson, 1989; Camasso \& Camasso, 1994).

In addition, type of practicing profession is one of the factors affecting time spent for patients. Wolinsky found that solo fee-for-service physicians spend nearly 4 minutes more with their patients overall, nearly 2 minutes more with their patients in the office, and over 11 minutes more with their patients in the hospital when compared to fee-for-service counterparts (Wolinsky \& Marder, 1982). The time spent with patients can also vary by gender of patients. Physicians tend to spend more time with female patients than males (Buller \&
Buller, 1987; Wallen, Waitzkin, \& Stoeckle, 1979). Because female patients ask more questions, they may be more knowledgeable regarding their illnesses and treatments. On the other hand, the patient's age is another factor on the physicians' time spent and communication style. The study showed that "Older patients, however, may visit the physician more frequently, so they are more familiar with medical procedures and have more opportunities to associate a physician's treatment with improvements in their health. The patient's age also may affect the quality of information provided by the physician. Increased time spent talking with the physician was related inversely to patients' satisfaction" (Buller \& Buller, 1987).

The amount of administrative work also impacts the time physicians can spend with patients. In addition to caring for patients, physicians have to do a number of administrative tasks, which takes about 8.7 hours each week, accounting for 16.6 percent of their total workweek. In 2008 , physicians spent 168.4 million hours on administrative work (Woolhandler \& Himmelstein, 2014). Types of office setting and organizational structure have been demonstrated to have significant impact on medical practice. Wolinsky found that "one of the most commonly assumed yet seldom documented attributes of HMOs is the fact that HMO enrollees must wait longer to see a physician and then get to spend less time with the physician than do their fee for-service counterparts" (Wolinsky \& Marder, 1982). In addition, organizational structure is also one of the factors affecting the total time spent between physicians and patients (Weigl, Müller, Zupanc, \& Angerer, 2009) as well as visit lengths can vary significantly by specialty, even among primary care disciplines (Dugdale et al., 1999).

Much of the early studies relating to time spent by physicians with patients in outpatient care focused on the relationship between time spent and patient satisfaction (Dugdale et al., 1999; Ha \& Longnecker, 2010; Lin et al., 2001; Tongue et al., 2005), payment method, physician specialty, patient knowledge, gender of patient, optimal visit length, and the impact of organizational structure. However, the previous research did not address how the ownership structure of physicians' employment status affects the time spent with patients. This study mainly focuses on how physicians' employment status is associated with time spent with patients, and also tries to estimate the effects of individual characteristics of patients and physicians on time spent with patients in outpatient settings.

\section{THEORETICAL FRAMEWORK}

The model of agency explains some aspects of human behavior, which can have different purposes and incentives according to the relationship between principles and agent (Eisenhardt, 1989). MacKenzie and Cronstein indicate that "conflict of interest refers to a set of conditions in which professional judgment concerning a primary interest (such as a patient's welfare or the validity of research) is unduly influenced by a secondary interest (such as financial gain)" (MacKenzie \& Cronstein, 2006). One of the publication defines the concept of a theory of the ownership structure of the firm and explains that a conflict in incentives leads to the problem. 
Because of differences in attitude, they can be inclined to take different actions (Jensen \& Meckling, 1976). In addition, two types of relevant problems are described as reason of the conflict, one is the agency problem that occurs because of conflicting goals of the principal and the agent, being difficult and expensive in verifying the agent's behavior. The second is the problem of 'risk-sharing' which occurs because of different attitudes toward risk on the part of the principal and the agent (Nilakant \& Rao, 1994). The thoughts of this theory may suggest that physicians acting as both provider and principal of health facility during producing process may have an incentive to increase their volume and decrease unit cost per patient providing more health care, namely caring for more patients in a limited time during day.

Spending less time with each patient in the limited working hours in a day means having more workload, more patients, patient responsibility, and exhaustion at end of the day. In other words, spending more time with each patient in the limited working hours in a day means having less work load, fewer patients, less patient responsibility, and less exhaustion. When considering the rate of physician per capita (there is less physician but more patient), it seems that health care facilities do not have demand problem. Given these circumstances, the latter is preferable to the first way in which physicians have to work harder. However, if maximizing benefit in terms of monetary terms or using fixed capital in more efficient way by decreasing unit cost per patient is considered as the main desire of physicians, spending less time with each patient might be case. Employment status can be a key factor that influences the physicians' preference between two choices. Certainly, there are some remarkable incentives such as type of payment for physicians that can impact the situation. If there is no remarkable incentive for the employees and contractors, it should not be expected for owners to sacrifice work. Most research in economics has focused on the reasons and solutions for this behavior (Eisenhardt, 1989; MacKenzie \& Cronstein, 2006). Especially, this difference is increasing as parallel with the total value therefore this study is going to focus to see the difference at the healthcare sector that has the highest expenditures per capita.

\section{METHOD}

\section{Data}

The data was pooled from the National Ambulatory Medical Care Surveys (NAMCS) in 2012, administrated by the National Center for Health Statistics of the Centers of Disease Control and Prevention. After excluding some missing and not applicable data, our final sample consisted of 74,304 patient visits.

\section{Study Variables}

The primary dependent variable in this study was the time spent by physicians during the visits. The time spent for waiting and zero values in the data were not included in calculating time spent with patients. This study expected time spent with each patient during an appointment might be affected by employment status of physicians and individual characteristics of physicians and patients. Employee status and
Table 1. Descriptive Statistics on Time Spent with Patients (in minutes)

\begin{tabular}{ccccc}
\hline $\mathbf{N}$ & Minimum & Maximum & Mean & Std. D. \\
\hline 74304 & 1 & 240 & 23.13 & 15.462 \\
\hline
\end{tabular}

individual characteristics of physicians were physician specialty, percent of revenue from FFS, percent of patient care revenue from capitation, region where majority of physician's sampled visits occurred while individual characteristics of patients were whether the patient has been seen in the practice before or not, type of payment, race, gender and age.

\section{Study Hypothesis}

The primary aim of this study is to test whether the employment status of practice show any effect on time spent by physicians with patients during an outpatient consultation. This study hypothesized that physicians who are employees or contractors spent more time with patients than physicians who were owners during the examination. The rationale behind of this assumption was the expectation that physicians who were owner of health care facility might have an incentive to decrease unit cost per patient by caring for more patient and spending less time per patient for increasing their profits in terms of monetary terms.

\section{Data Analysis}

The relationship between independent variables that were individual characteristics of physicians and patients as well as physicians' employee status and dependent variable that was total time spent by physicians were examined by using ANOVA and t-test for independent samples. Multiple linear regression analysis was used to test the relationship between time of spent per patient and patients' characteristics as well as physician payment type and employee status. Statistical significance was assessed at the 5 percent level. STATA statistical software version 13 was used for analyzing the data.

\section{FINDINGS}

Mean time spent per patient was calculated to be 23.13 $( \pm 15.46)$ in minutes (Table 1$)$. However, time of spent per patient varied a lot across patient and employee status as well as payment type groups (min: 1 minute, max: 240 minutes) according to the results.

Table 2 also describes the sample of this study. The majority of patients were female (57.5\%) and patients (82.5\%) who were treated before at the facility. Almost one third of patients (29.8\%) was aged between 45 to 64 years old. The big majority was white (86.3\%) and patients in the sample were almost equally distributed among the regions. Private insurance was the highest portion of payment type, whereas Medicare and Medicaid were $28 \%$ and $11 \%$, respectively. Less than 5 percent of type of payment was in the self-pay category. 
Table 2. Descriptive Statistics on Independent Variables and Their Association with Time Spent with Patients

\begin{tabular}{|c|c|c|c|c|c|c|}
\hline Patient and Physician Characteristics & Freq. & $\%$ & Mean_TS & St.D. & $\mathrm{F} / \mathrm{t}$ & $\mathbf{P}$ \\
\hline \multicolumn{7}{|l|}{ Patient Sex } \\
\hline Female & 43860 & 57.5 & 23.1 & 15.3 & -0.467 & 0.641 \\
\hline Male & 32470 & 42.5 & 23.2 & 15.6 & & \\
\hline Total & 76330 & 100.0 & 23.1 & 15.5 & & \\
\hline \multicolumn{7}{|l|}{ Has the Patient Been Seen Before? } \\
\hline Yes, established patient & 62993 & 82.5 & 22.4 & 14.7 & -28.926 & 0.000 \\
\hline No, new patient & 13337 & 17.5 & 26.7 & 18.4 & & \\
\hline Total & 76330 & 100.0 & 23.1 & 15.5 & & \\
\hline \multicolumn{7}{|l|}{ Patient Age } \\
\hline Under 15 years & 11739 & 15.4 & 20.8 & 12.4 & 73.249 & 0.000 \\
\hline $15-24$ years & 5621 & 7.4 & 22.5 & 15.6 & & \\
\hline $25-44$ years & 14541 & 19.1 & 23.5 & 16.0 & & \\
\hline $45-64$ years & 22715 & 29.8 & 24.0 & 16.0 & & \\
\hline 65-74 years & 11235 & 14.7 & 23.6 & 16.5 & & \\
\hline 75 years and over & 10479 & 13.7 & 23.1 & 15.2 & & \\
\hline Total & 76330 & 100.0 & 23.1 & 15.5 & & \\
\hline \multicolumn{7}{|l|}{ Patient Race } \\
\hline White & 65890 & 86.3 & 23.1 & 15.5 & 12.341 & 0.000 \\
\hline Black & 6889 & 9.0 & 22.5 & 14.8 & & \\
\hline Other & 3551 & 4.7 & 24.1 & 15.4 & & \\
\hline Total & 76330 & 100.0 & 23.1 & 15.5 & & \\
\hline \multicolumn{7}{|l|}{ Type of Payment } \\
\hline Private insurance & 37647 & 52.7 & 22.8 & 15.1 & 70.096 & 0.000 \\
\hline Medicare & 20157 & 28.2 & 23.3 & 15.9 & & \\
\hline Medicaid or CHIP & 8104 & 11.3 & 21.8 & 13.6 & & \\
\hline Worker's compensation & 778 & 1.1 & 22.4 & 15.9 & & \\
\hline Self-pay & 3168 & 4.4 & 28.1 & 19.9 & & \\
\hline No charge/Charity & 150 & 0.2 & 29.9 & 26.0 & & \\
\hline Other & 1439 & 2.0 & 24.0 & 16.7 & & \\
\hline Total & 71443 & 100.0 & 23.1 & 15.5 & & \\
\hline \multicolumn{7}{|l|}{ Type of Specialty } \\
\hline Primary care specialty & 32290 & 42.3 & 21.4 & 13.2 & 930.295 & 0.000 \\
\hline Surgical care specialty & 17308 & 22.7 & 21.3 & 15.3 & & \\
\hline Medical care specialty & 26732 & 35.0 & 26.5 & 17.5 & & \\
\hline $\begin{array}{l}\text { Total } \\
\end{array}$ & 76330 & 100.0 & 23.1 & 15.5 & & \\
\hline \multicolumn{7}{|l|}{ Employment Status of Physician } \\
\hline Full-owner & 27677 & 36.6 & 23.9 & 15.7 & 50.007 & 0.000 \\
\hline Part-owner & 22699 & 30.0 & 22.2 & 14.4 & & \\
\hline Employee & 22736 & 30.0 & 23.3 & 16.2 & & \\
\hline Contractor & 2595 & 3.4 & 22.9 & 16.3 & & \\
\hline Total & 75707 & 100.0 & 23.1 & 15.5 & & \\
\hline \multicolumn{7}{|c|}{ Percent of revenue from patient payments } \\
\hline 0-25 percent & 64697 & 95.4 & 22.7 & 15.2 & 239.648 & 0.000 \\
\hline $26-50$ percent & 1383 & 2.0 & 26.2 & 17.8 & & \\
\hline 51-75 percent & 429 & 0.6 & 27.3 & 18.1 & & \\
\hline 76-100 percent & 1275 & 1.9 & 34.2 & 20.8 & & \\
\hline Total & 67784 & 100.0 & 23.0 & 15.4 & & \\
\hline \multicolumn{7}{|l|}{ Percent of revenue from fee-for-service } \\
\hline $0-25$ percent & 9224 & 16.1 & 23.7 & 15.6 & 12.072 & 0.000 \\
\hline $26-50$ percent & 3490 & 6.1 & 22.9 & 15.3 & & \\
\hline $51-75$ percent & 4296 & 7.5 & 23.5 & 14.1 & & \\
\hline 76-100 percent & 40260 & 70.3 & 22.7 & 15.0 & & \\
\hline Total & 57270 & 100.0 & 23.0 & 15.1 & & \\
\hline \multicolumn{7}{|l|}{ Percent of revenue from capitation } \\
\hline $0-25$ percent & 51131 & 89.8 & 22.8 & 15.1 & 20.180 & 0.000 \\
\hline 26-50 percent & 2458 & 4.3 & 23.5 & 12.5 & & \\
\hline 51-75 percent & 1224 & 2.2 & 23.6 & 14.0 & & \\
\hline 76-100 percent & 2115 & 3.7 & 25.4 & 17.5 & & \\
\hline Total & 56928 & 100.0 & 23.0 & 15.1 & & \\
\hline \multicolumn{7}{|l|}{ Region Visits Occurred } \\
\hline Northeast & 10044 & 13.2 & 24.3 & 15.2 & 59.242 & 0.000 \\
\hline Midwest & 18797 & 24.6 & 22.7 & 14.8 & & \\
\hline South & 29060 & 38.1 & 22.5 & 15.8 & & \\
\hline West & 18429 & 24.1 & 24.0 & 15.5 & & \\
\hline Total & 76330 & 100.0 & 23.1 & 15.5 & & \\
\hline
\end{tabular}


Initial findings suggested time of spent per patient might be affected because of patient and physician characteristics. The association between time of spent for patient and patient and physician characteristics was tested by ANOVA and t-test for independent samples and the results were provided in Table 3.

Over fourty percent (42.3\%) of patients were examined by physicians in primary care specialty while $35 \%$ was seen by physicians in medical care specialty. More than one third of patients $(36.6 \%)$ were seen by physicians who were the owners of the facility where patients were examined. Only a small partion of patients (3.4\%) were examined by physicians working by contractor base. Over one third of patiens (34.2\%) was treated at health care facilities whose revenues came from patient payments at the reate of 76 to 100 percent.Health care facilities in which the big majority of patients were examined received their revenues mostly from fee for service (70.3 percent), but less revenue from capitation.

Both female and male patients were allocated almost same amount of time during examination by physicians, and there was no statistically significant difference $(p>0.05)$. Physicians spent additional 4 minutes in average for examining for new patients (26.7 minutes) compared to previous patients of the facility, and the difference between time of spent for new and previous patients was found to be statistically significant $(p<0.05)$. According to the results, physicans also tended to spend more time to those patients who were aged reletively older. For instance, patients who were aged under 15 years old were spent 20.8 minutes in average and this was less compared to all other average times spent for other patients in other age categories, and ANOVA results showed that there was statistically signgicant different across age groups $(p<0.05)$. Patient describing themselves in other races rather than black or white were spent more time for examination (24.1 minutes in average) by physicians compared to white and black patients while patients living in Northeast and West regions were allocated more time (almost 24 minutes in both regions) by physicians compared to those living in Midwest and South regions, and the differences were found to be statistically significant $(\mathrm{p}<0.05)$. Even if the number of self-pay or nocharge and charity patients were not too many in the sample (4.4 and 0.2 percent, respectively), those were the patient categories that were spent more time (28.1 and 29.9 minutes in average, respectively) during examination by physicians. However, those patients who were paid by medicaid or CHIP were spent the least time (21.8 minutes in average), and the differences in terms of time of spent per patient were found to be statistically significant $(\mathrm{p}<0.05)$. The patients of medicl specialy were also spent more time (26.5 minutes in average) compared primary care and surgical care specialty patients (over 21 minutes for both patient groups). Patients seen by physicians who were owner (23.9 minutes), or employees (23.3) of the facility were spent more time compared to patients examined by part-owner (22.2 minutes) and conrtactor (22.9 minutes) physicians. The results showed that time of spent for examination differed statistically across employee status of physicians at the facility $(p<0.05)$. According to the results, the facilities receiving their revenues at the rate of $76-100$ percent from patient payments spent more examination time per patient (34.2 minutes in average), and this amount of time was found to be statistically higher $(p<0.05)$ compared to health facilities in other categories. The results also suggested that those patients seen in the facilities whose revenue share from fee fro service was at the rate of 0 25 percent were spent more time ( 23.7 minutes in average) while patients seen in the facilities whose revenue from capitation was at the rate of 76-100 percent were also spent more time (25.4 minutes in average) compared to other health facilities, and the differences in terms of time spent per patient were found to be statistically significant $(\mathrm{p}<0.05)$.

Three different linear regression models were run to estimate the effects of patient characteristics and physician employee status and paymet type variables on the time spent per patient, and the results were provided in Table 3 . The results of model 1 estimating the effects of patient characteristics on time spent showed that there was a statistically significant relationship between time spent per patient and the variables of age, race, being new patient, and region. According to the results, physicians were more likely to spend more time to those patients who were aged more than 15 years old, were from other race rather than white, were new patients, and were seen in Northeast part of the country. The results of model 1 estimating the effects of health facility related characteristics on time spent per patient also revealed that patients that were seen in the health care facilities located in Northeast regions, received care from medical care specialities, were paid by self or not paying and charity patients were more likely to be receive care in longer times compared to other patients in other categories. The results also showed that those health facilities with more revenues from patient payments and capitation were more likely to increase their avarage time of spent per their patients compared to health facilities with lower revenue from patient payments and capitation. According to the results of model 2, health facilities with less revenue from fee for seervices were also more likely to spend more time for their patients. If a patient was seen by a physician who was the full owner of health facility, he or she was more likely to be treated in longer times compared to other patients were seen by a physician who were part owner, emloyee or contractor in health facility.

The results of model 3 estimating the effects of both patient characteristics and payment type and employee status on time spent per patient at the same time confirmed the results of Model 1 and Model 2. However, the effect of race variable on time spent became insignificant in Model 3 while patients who were paid by Medicaid or CHIP were also more likely to be treated in longer times like self paid or charity patients compared to patients who were paid by private insurance (please see Table 3). 
Table 3. Linear Regression Results on The Effects of Individual Characteristics of Patients and Physicians on Time Spent with Patients

\begin{tabular}{|c|c|c|c|c|c|c|c|c|c|c|c|c|}
\hline \multirow{2}{*}{ Variables } & \multicolumn{4}{|c|}{ Model 1} & \multicolumn{4}{|c|}{ Model 2} & \multicolumn{4}{|c|}{ Model3 } \\
\hline & B & St.E. & $\mathbf{t}$ & & B & St.E. & $\mathbf{t}$ & & B & St.E. & $\mathbf{t}$ & \\
\hline \multicolumn{13}{|l|}{ Patient Age } \\
\hline Under 15 years & Ref. & & & & & & & & Ref. & & & \\
\hline 25-44 years & 2.44 & 0.19 & 12.53 & $* * * *$ & & & & & 1.68 & 0.23 & 7.17 & ***** \\
\hline 45-64 years & 3.09 & 0.18 & 17.42 & $* * * *$ & & & & & 2.46 & 0.22 & 11.1 & $* * *$ \\
\hline $65-74$ years & 2.93 & 0.21 & 14.31 & $* * * *$ & & & & & 2.58 & 0.30 & 8.51 & $* * *$ \\
\hline 75 years and over & 2.47 & 0.21 & 11.8 & $* * *$ & & & & & 2.27 & 0.32 & 7.06 & $* * *$ \\
\hline \multicolumn{13}{|l|}{ Patient Sex } \\
\hline Female & Ref. & & & & & & & & Ref. & & & \\
\hline Male & 0.14 & 0.11 & 1.23 & & & & & & 0.10 & 0.13 & 0.72 & \\
\hline \multicolumn{13}{|l|}{ Patient Race } \\
\hline White & Ref. & & & & & & & & Ref. & & & \\
\hline Black & -0.20 & 0.20 & -0.99 & & & & & & 0.23 & 0.23 & 0.98 & \\
\hline Other & 0.66 & 0.27 & 2.42 & *** & & & & & 0.44 & 0.31 & 1.41 & \\
\hline \multicolumn{13}{|l|}{ Has the Patient Been Seen Before? } \\
\hline $\begin{array}{c}\text { No, new patient } \\
\end{array}$ & 4.25 & 0.15 & 28.65 & ***** & & & & & 4.24 & 0.18 & 23.71 & **** \\
\hline \multicolumn{13}{|l|}{ Region Visits Occurred } \\
\hline Northeast & Ref. & & & & Ref. & & & & Ref. & & & \\
\hline Midwest & -1.77 & 0.19 & -9.19 & $* * * *$ & -1.65 & 0.23 & -7.05 & $* * * *$ & -1.76 & 0.23 & -7.54 & $* * * *$ \\
\hline South & -1.89 & 0.18 & -10.4 & ***** & -2.01 & 0.22 & -9.18 & *** & -2.14 & 0.22 & -9.8 & $* * *$ \\
\hline West & -0.61 & 0.19 & -3.14 & ***** & -0.52 & 0.24 & -2.21 & $* *$ & -0.70 & 0.24 & -2.99 & $* * *$ \\
\hline \multicolumn{13}{|l|}{ Type of Payment } \\
\hline $\begin{array}{l}\text { Private insurance } \\
\end{array}$ & & & & & Ref. & & & & Ref. & & & \\
\hline Medicare & & & & & 0.18 & 0.15 & 1.17 & & -0.15 & 0.23 & -0.63 & \\
\hline Medicaid or CHIP & & & & & -0.15 & 0.22 & -0.68 & & 0.60 & 0.22 & 2.68 & $* * * *$ \\
\hline Worker's compensation & & & & & -0.66 & 0.61 & -1.08 & & -0.83 & 0.61 & -1.36 & \\
\hline Self-pay & & & & & 1.61 & 0.40 & 4.02 & **** & 1.18 & 0.40 & 2.96 & **** \\
\hline No charge/Charity & & & & & 3.16 & 1.49 & 2.13 & $* *$ & 3.00 & 1.48 & 2.03 & *** \\
\hline Other & & & & & 0.97 & 0.49 & 1.98 & $* *$ & 0.47 & 0.49 & 0.96 & \\
\hline \multicolumn{13}{|l|}{ Type of Specialty } \\
\hline $\begin{array}{r}\text { Primary care specialty } \\
\end{array}$ & & & & & Ref. & & & & Ref. & & & \\
\hline \multicolumn{13}{|l|}{ Employment Status of Physician } \\
\hline Full-owner & & & & & Ref. & & & & Ref. & & & \\
\hline Part-owner & & & & & -1.24 & 0.16 & -7.8 & **** & -1.21 & 0.16 & -7.61 & $* * *$ \\
\hline Employee & & & & & -0.55 & 0.17 & -3.26 & **** & -0.70 & 0.17 & -4.14 & ***** \\
\hline Contractor & & & & & -1.31 & 0.37 & -3.51 & **** & -1.41 & 0.37 & -3.8 & **** \\
\hline Percent of revenue from patient $p$ & ents & & & & & & & & & & & \\
\hline $0-25$ percent & & & & & Ref. & & & & Ref. & & & \\
\hline 26-50 percent & & & & & 3.63 & 0.46 & 7.9 & $* * *$ & 3.71 & 0.46 & 8.12 & $* * *$ \\
\hline $51-75$ percent & & & & & 4.41 & 0.79 & 5.57 & **** & 4.62 & 0.79 & 5.85 & **** \\
\hline $76-100$ percent & & & & & 9.53 & 0.60 & 15.79 & $* * *$ & 10.06 & 0.60 & 16.76 & $* * *$ \\
\hline Percent of revenue from fee-for-s & & & & & & & & & & & & \\
\hline $0-25$ percent & & & & & Ref. & & & & Ref. & & & \\
\hline 26-50 percent & & & & & -0.07 & 0.33 & -0.2 & & -0.05 & 0.33 & -0.16 & \\
\hline 51-75 percent & & & & & 0.26 & 0.32 & 0.81 & & 0.27 & 0.32 & 0.86 & \\
\hline $76-100$ percent & & & & & -0.51 & 0.21 & -2.41 & * & -0.40 & 0.21 & -1.92 & * \\
\hline Percent of revenue from capitatio & & & & & & & & & & & & \\
\hline $0-25$ percent & & & & & Ref. & & & & Ref. & & & \\
\hline 26-50 percent & & & & & 0.40 & 0.36 & 1.09 & & 0.33 & 0.36 & 0.9 & \\
\hline $51-75$ percent & & & & & 0.14 & 0.48 & 0.28 & & 0.11 & 0.47 & 0.24 & \\
\hline 76-100 percent & & & & & 1.20 & 0.40 & 3.00 & **** & 1.14 & 0.40 & 2.86 & $* * *$ \\
\hline Constant & 21.35 & 0.21 & 99.78 & ***** & 23.23 & 0.29 & 78.86 & **** & 21.29 & 0.34 & 62.8 & **** \\
\hline $\mathrm{R} 2$ & 0.0182 & & & & 0.0405 & & & & 0.0533 & & & \\
\hline Adj. R & 0.0181 & & & & 0.04 & & & & 0.0527 & & & \\
\hline $\mathrm{F}$ & 114.97 & & & & 93.55 & & & & 89.82 & & & \\
\hline $\mathrm{p}$ & 0.000 & & & & 0.000 & & & & 0.000 & & & \\
\hline
\end{tabular}

*: Significant at $\mathrm{p}$-value $=0.05$

**: Significant at less than p-value of 0.05

***: Significant at less than p-value of 0.01 


\section{DISCUSSION AND CONCLUSION}

The results of this study revealed that time of spent per patient was affected significantly by individual characteristics of patients and physicians. Time spent per patient was affected by age, race, and type of payment according to the results. The findings on spending more time for relatively older, white, and those patients who were self-pay were consistent with the findings of previous studies (Buller \& Buller, 1987; Rhodes et al., 2001; Wolinsky \& Marder, 1982). However, it is interesting to see that time spent per patient was the highest for the patients with no charge or charity patients. The poor health status or complex diseases of relatively poor people might be potential explanation of this finding.

Individual characteristics of physicians were also found to be important factors affecting time spent per patient in this study. Those physicians, who worked in medical care specialty, were practicing in Northeast and West part of the country, and practicing in health care facilities whose revenue mostly came from capitation and patient payments were more likely to spend more time for their patients during visits. These results were also consistent with the previous studies (Dugdale et al., 1999; Wolinsky \& Marder, 1982).

However, the study hypothesis set in light of theoretical framework was rejected. This study expected those physicians, caring for patients but also be owners of health care facility in which they were practicing, spend less time for their patients and care for more patients to increases their revenues or decrease unit costs per patient. The results indicated that physicians who were full-owner had actually spent more time compared to other physicians practicing in other categories. For instance, a full-owner physician spent average 1.7 minutes more for a patient while a part-owner physician spent average 22.2 minutes for a patient.

This finding might be explained by different factors. The first factor might be a marketing theory. Marketing approach called Leaky-Bucket Theory suggests concentrating on existing customers be better than finding new customers because finding new customer is five times costly than holding previous customers by making them loyal and satisfied patients (Dowling \& Uncles, 1997; O’Malley \& Tynan, 2001). In light of this approach, patient satisfaction that is correlated with time spent for patient might have accepted to be more important goal than seeing more patient that might cause patient dissatisfaction by full-owner physician practitioners. The second factor might be distinguished characteristics of health sector. Health sector is usually characterized by uncompetitive conditions, uncertain demand, unequal supplydemand balance, access limitations in market, unaware patients about the services, heterogeneous services, the role of nonprofit organizations, and the weak correlation between the prices and the real costs (Torun, Celik, \& Younis, 2012). Under the circumstances that there is no demand problem (or over demand), full-owner physicians might have played the role of perfect agent for their patients because they might think that concentrating on previous customers or sacrificing time from patients creates ethical dilemmas (Kälvemark, Höglund, Hansson, Westerholm, \& Arnetz, 2004; Thompson, 1993). The third factor full-owner physician practitioners might be acting as strategic planners. They might be more interested in the long run for their business and try to make all patients be loyal customers by spending more time with their patients. Due to new patients were spent more time with physicians based on the result, we might argue that owners want to increase patients' satisfaction and loyalty so that they spent more time with them than employees and contractors did.

Health is the most important thing that a person has in the world and is the last thing a person wants to lose. Therefore, a person's health has a remarkable relationship with their happiness (Aydin, 2019). Whenever there is any health issue, physicians are seen regardless the cost. Inherently, time spent with the physician is an important indicator for patients to see the total care. Based on this assumption, patient satisfaction cannot be fulfilled without a sufficient amount of time spent with the physician during the examination. In other words, patient satisfaction has a parallel relationship with the time spent by physicians. As the U.S. seeks to increase the quality of health care, both the quality and quantity of time physicians spend with patients will be an increasingly important factor.

In light of the findings, the following recommendations might be suggested for health care mangers and future studies:

- Policy makers and managers should consider monitoring time spent with patients in order to improve efficiency and quality indicators in health care facilities, or they may define an acceptable standard visit length without sacrificing efficiency, quality, and patient satisfaction.

- The applicability of leaky-bucket theory and the thoughts of economic theories might be revisited in today's health care environment.

- A qualitative study should be carried out to learn the incentives of full-owner physician practitioners for spending more time with their patients.

This study has some notable limitations. First, it evaluated only the time spent with physicians during the examination. The relationship between waiting time to see physicians before the examination should be evaluated based on the employment status in the future research. Second, future work should examine that how physicians time spending impact on the patients outcome. Additionally, the effect of language barrier of foreign-born patients and patients' exam frequency on the total time spent should be worked in future research.

\section{REFERENCES}

Anderson, R. T., Camacho, F. T., \& Balkrishnan, R. (2007). Willing to wait?: the influence of patient wait time on satisfaction with primary care. BMC Health Services Research, 7(1), 1. https://doi.org/10.1186/1472-6963-7-31

Andersson, S.-O., \& Mattsson, B. (1989). Length of consultations in general practice in Sweden: views of doctors and patients. Family practice, 6(2), 130-134. https://doi.org/10.1093/fampra/6.2.130

Aydin, S. (2019). Factors Affecting Patient Satisfaction With Healthcare System Of Turkey. 
Buller, M. K., \& Buller, D. B. (1987). Physicians' communication style and patient satisfaction. Journal of Health and Social Behavior, 375-388. https://doi.org/10. $2307 / 2136791$

Camasso, M. J., \& Camasso, A. E. (1994). Practitioner productivity and the product content of medical care in publicly supported health centers. Social Science \& Medicine, 38(5), 733-748. https://doi.org/10.1016/02779536(94)90464-2

Dowling, G. R., \& Uncles, M. (1997). Do customer loyalty programs really work? MIT Sloan management review, 38(4), 71.

Dugdale, D. C., Epstein, R., \& Pantilat, S. Z. (1999). Time and the patient-physician relationship. Journal of general internal medicine, 14(S1), 34-40. https://doi.org/10.1046/ j.1525-1497.1999.00263.x

Eisenhardt, K. M. (1989). Agency theory: An assessment and review. Academy of management review, 14(1), 57-74.

Ha, J. F., \& Longnecker, N. (2010). Doctor-patient communication: a review. The Ochsner Journal, 10(1), 3843. Retrieved from http://www.ncbi.nlm.nih.gov/pmc/ articles/PMC3096184/pdf/11524-5012-10-1-38.pdf

Hollingsworth, J. C., Chisholm, C. D., Giles, B. K., Cordell, W. H., \& Nelson, D. R. (1998). How do physicians and nurses spend their time in the emergency department? Annals of emergency medicine, 31(1), 87-91. https://doi.org/10.1016/ S0196-0644(98)70287-2

Jensen, M. C., \& Meckling, W. H. (1976). Theory of the firm: Managerial behavior, agency costs and ownership structure. Journal of financial economics, 3(4), 305-360. https://doi.org/10.1016/0304-405X(76)90026-X

Kälvemark, S., Höglund, A. T., Hansson, M. G., Westerholm, P., \& Arnetz, B. (2004). Living with conflicts-ethical dilemmas and moral distress in the health care system. Social Science \& Medicine, 58(6), 1075-1084. https://doi.org/10.1016/ S0277-9536(03)00279-X

Kaplan, S. H., Greenfield, S., Gandek, B., Rogers, W. H., \& Ware, J. E. (1996). Characteristics of physicians with participatory decision-making styles. Annals of Internal Medicine, 124(5), 497-504. https://doi.org/10.7326/00034819-124-5-199603010-00007

Kaplan, S. H., Greenfield, S., \& Ware Jr, J. E. (1989). Assessing the effects of physician-patient interactions on the outcomes of chronic disease. Medical Care, 27(3), S110S127. https://doi.org/10.1097/00005650-198903001-00010

Laine, C., Davidoff, F., Lewis, C. E., Nelson, E. C., Nelson, E., Kessler, R. C., \& Delbanco, T. L. (1996). Important elements of outpatient care: a comparison of patients' and physicians' opinions. Annals of Internal Medicine, 125(8), 640-645. https://doi.org/10.7326/0003-4819-125-8199610150-00003

Lin, C.-T., Albertson, G. A., Schilling, L. M., Cyran, E. M., Anderson, S. N., Ware, L., \& Anderson, R. J. (2001). Is patients' perception of time spent with the physician a determinant of ambulatory patient satisfaction? Archives of Internal Medicine, 161(11), 1437-1442. https://doi.org/10. 1001/archinte.161.11.1437
MacKenzie, C. R., \& Cronstein, B. N. (2006). Conflict of interest. HSS Journal ${ }^{\circledR}, 2(2), 198-201$. https://doi.org/10. 1007/s11420-006-9016-1

Mamlin, J. J., \& Baker, D. H. (1973). Combined time-motion and work sampling study in a general medicine clinic. Medical Care, 449-456. https://doi.org/10.1097/00005650197309000-00010

McDonald, J., \& Dzwonczyk, R. (1988). A time and motion study of the anaesthetist's intraoperative time. British Journal of Anaesthesia, 61(6), 738-742. https://doi.org/10. 1093/bja/61.6.738

Nilakant, V., \& Rao, H. (1994). Agency theory and uncertainty in organizations: An evaluation. Organization studies, 15(5), 649-672. https://doi.org/10.1177/017084069401500 501

O’Malley, L., \& Tynan, C. (2001). Reframing relationship marketing for consumer markets. Interactive Marketing, 2(3), 240-246. https://doi.org/10.1057/palgrave.im. 4340094

Pollak, K. I., Krause, K. M., Yarnall, K. S., Gradison, M., Michener, J. L., \& Østbye, T. (2008). Estimated time spent on preventive services by primary care physicians. $B M C$ Health Services Research, 8(1), 1. https://doi.org/10.1186/ 1472-6963-8-245

Rhodes, D., McFarland, K. F., Finch, W. H., \& Johnson, A. O. (2001). Speaking and interruptions during primary care office visits. Family Medicine-Kansas City-, 33(7), 528-532.

Roter, D. L., Hall, J. A., \& Katz, N. R. (1988). Patient-physician communication: a descriptive summary of the literature. Patient Education and Counseling, 12(2), 99-119. https://doi.org/10.1016/0738-3991(88)90057-2

Thompson, D. F. (1993). Understanding financial conflicts of interest. New England Journal of Medicine, 329(8), 573-576. https://doi.org/10.1056/NEJM199308193290812

Tongue, J. R., Epps, H. R., \& Forese, L. L. (2005). Communication skills for patient-centered care. I Bone Joint Surg Am, 87(3), 652-658. https://doi.org/10.2106/ 00004623-200503000-00027

Torun, N., Celik, Y., \& Younis, M. (2012). Competition among Turkish hospitals and its effect on hospital efficiency and service quality. Journal of health care finance, 40(2), 42-58.

Wallen, J., Waitzkin, H., \& Stoeckle, J. (1979). Physician stereotypes about female health and illness: A study of patient's sex and the informative process during medical interviews. Women \& Health, 4(2), 135-146. https://doi.org/10.1300/J013v04n02_03

Weigl, M., Müller, A., Zupanc, A., \& Angerer, P. (2009). Participant observation of time allocation, direct patient contact and simultaneous activities in hospital physicians. BMC Health Services Research, 9(1), 1. https://doi.org/10. 1186/1472-6963-9-110

Wolinsky, F. D., \& Marder, W. D. (1982). Spending Time with Patients the Impact of Organizational Structure on Medical Practice. Medical Care, 1051-1059. https://doi.org/10.1097/ 00005650-198210000-00008 
Woolhandler, S., \& Himmelstein, D. U. (2014). Administrative Work Consumes One-Sixth of US Physicians' Working Hours and Lowers their Career Satisfaction. International Journal of Health Services, 44(4), 635-642. https://doi.org/10.2190/HS.44.4.a
Yarnall, K. S., Pollak, K. I., Østbye, T., Krause, K. M., \& Michener, J. L. (2003). Primary care: is there enough time for prevention? American Journal of Public Health, 93(4), 635-641. https://doi.org/10.2105/AJPH.93.4.635 